with the fulcrum so adjusted as to revolve at the back of a steel plate, which remained stationary, and afforded some protection to the gum.

$I$ have no intention of claiming for myself any merit whatever for the construction of the instruments which $I$ have now in use. They were made under the direction and from the patterns of those used for the last twenty years, by Mr. Charles Bromley, of Southampton, my instructor in dental surgery, to whom I believe the credit of their invention to be justly due. I am merely desirous of bearing testimony to the decided superiority of such instruments over every kind of key-instrument which has fallen under my observation. I do not deny that a tooth may be extracted safely and expedi. tiously with the key, but I contend that the proper use of the forceps is more easily acquired, and that their application is safer, infinitely less painful, and more than equally effective. I have the honour to be, Sir, your obedient servant,

24, Mortimer-street, Cavendish-square, June, $184 \mathrm{l}$.

\section{DISEASES OF THE TEETH} OF PERSONS LIVING IN DAMP, LOW PLACES.

\section{To the Editor of THE LANCET.}

SIR :-As you inserted my last communication, on the importance of pathological information to dental practitioners, you will confer on me an additional favour, by inserting the following remarks.

From extensive observations in different localities, 1 have ascertained that in all low, damp places, and near the margin of rivers and lakes, the inhabitants have generally very bad teeth, arising from the deranged state of their digestive organs. The teeth have the appearance of having been acted upon by weak acids, being somewhat dark and transparent, or rather translucent, owing to the lime being gradually removed from them. They are also very brittle, and ultimately crumble to pieces. In the early stages of this disease, great complaint is often made of pain whenever the temperature of the atmosphere becomes suddenly lower; and this arises from the enamel being so much thinuer than it ought to be. The consequences, noticed above, might be prevented by the use of alkaline moutbwashes, and in attending to the dyspeptic symptoms, the practitioner being regulated in his treatment by whatever may have caused derangement of the digestive organs. It is now some years since that I first stated my own observations on this disease of the teetb, in a conversation with the late wor- thy and talented Dr. Alderson, of Hull, in answer to a question he put to me, "Why the people of that town had generally such bad teeth?" 'The substance of that reply I have already given, but the facts on which $I$ based my opinion must be alluded to. It will, however, be important, in order to elucidate the subject, and render my facts more interesting, that I should furnish some notion of the topographical and geological peculiarities of the locality in question. Hull is a very flat, low-built town, situated on an alluvial deposit, principally composed of a stiff, tenacious clay, which retains moisture, and which is, therefore, the greater part of the year very damp. The town itself is intersected with canals, which connect the different docks; on one side flows the narrow, sluggish river $\mathrm{Hull}$, and on another side is the broad, low bank of the noble Humber, so that the town is surrounded with water, and the atmosphere is the greater part of the year in a humid state, and very cold. If there is any disorder in Hull which may be considered endemical it is dyspepsia, with its numerous auxiliaries. Of course, the consequences of stomach derangement will be more or less injurious to the mouth, in proportion as they are aggravated or mitigated by the filthy or the cleanly habits of the people. The working classes of $\mathrm{Hull}$ have generally very spongy gums, with copious deposits of tartar, as well as bad teeth; but $I$ will not say that this arises altogether from uncleanliness, as it may be partly owing to their unnutritious diet, \&c.

In order to satisfy my own mind, I visited many places built on the banks of rivers, or situated in low fenny and marshy districts, in order to ascertain whether the results $\mathbf{I}$ had noticed in Hull, Gainsborough, Boston, \&c. \&c., were owing to any accidental circumstances, or were constant effects induced by the causes previously suggested. My former conclusious were confirmed, and ought, from the constancy of the facts, viz., that in such localities there is great stomach derangement and bad teeth, to be considered correct, if we admit the accuracy and importance of the principles of inductive philosophy. The geognostic and other local peculiarities in meny of these places were similar to those observed at $\mathrm{Hull}-$ cold and damp soil and a humid atmosphere, and all those who resided near the water had bad carious teeth, with dyspeptic complaints.

So much for the direct proof; but there is another circumstance to be mentioned which may be considered indirect evidence, and which I consider to be somewhat interesting, in connection with my present communication; namely, that in such towns as Doncaster, Gainsborough, Lincoln, \&c. \&c., the people resiaing near the rivers in these respective places, had worse teeth than the other inhabitants who resided in drier locali* 
ties, and more distant from the water ; precisely indicating in the strongest manner what was observed when the Asiatic cholera was scourging this and other countriesthat the unhealthy districts were those near to the rivers, and in low, damp localities, and that in all such places the disease was most fatal. I am, Sir, with great respect, yours truly,

J. L. Levison. 25, Upper Temple-street, Birmingham, May 28, 1841.

\section{EXTRACTION OF TEETH.}

\section{To the Editor of The LANCET.}

SIR:-I read with much pleasure the paper of Mr. Stevens on the Tooth-Key In. strument, in your last Number, and can from twenty years' experience in military and provincial practice, in both of which dental surgery is a part of the surgeon's duty, confidently assert that the principles he lays down are of great importance; in fact, most of the failures with the keyinstrument, I am confident, arise from igno. rance of the resolution of the mechanical forces. I have acted upon the principles he so well states for many years; and I made many years ago some diagrams which are essentially the same as his, and to demonstrate the same principles. I showed them to a dentist, who informed me that Bell had already given the same information to the profession in his works. I have not seen Mr. Bell's works, but as I supposed my inform. ant to be accurate in his statement, I was unwilling to build upon another man's foundation, and remained silent on the subject. I would beg leave to state that the rules I give to my pupils in using the key are to employ the smallest claw that will fairly embrace the tooth; to keep the elbow fixed, and to make the turn with the supination of the hand, keeping the forearm in a line continuous with the shaft of the instrument. These cautions, with care, common mechanical skill, and some anatomical knowledge, will, if the instrument is well constructed, prevent many of the cruel operations that patients sometimes undergo.

Tooth-drawing is a severe operation, and any one who can suggest a means of rendering it less painful and more successful deserves the thanks of the public, and such are due to Mr. Stevens, if his remarks are original; if not, the subject is well worth urging upon the attention of the profession. I am, Sir, your obedient servant,

\section{J. Houlton.}

London, May 31, 1841.

\section{NAVAL ASSISTANT-SURGEONS.}

\section{To the Editor of The Lancet.}

SiR:-If you deem the following worth a place in your popular Journal, you are at liberty to make any use of it. I am, Sir, your very humble servant,

J. Tweeddale, M.D.

87, St. Martin's-Iane, May 25, 1841.

At the annual general meeting of the off. cers and supporters of the Royal Naval School, which was held at the Horticultural Society's room, 21, Regent-street, on last Wednesday, to receive the report of the council of administration for the past year; the Right Hon. Sir George Cockburn, president, in the chair; a notice of motion was read by the secretary, placed on the book last year by myself : the object of which was to secure for the children of assistantsurgeons of the royal navy the benefits of the institution. And which motion was rejected, and rejected, too, by a large majority, without so much as an attempt to impugn the arguments that had been advanced in its favour. Their exclusion from the benefits of the school, cannot but be considered as at once impolitic and unjust: impolitic, because the greater the number of pupils at the fall yearly cost of $25 l$. per annum, the better for the school; unjust, for there is no person on board ship, whose services are more valuable in time of need than those of the assistant-surgeon. The council are ac. customed to congratulate themselves on the increase of the number of pupils, yet oppose that increase by refusing to admit the sons of the members of a most responsible branch of their profession. And why? because they are not permitted to mess in the wardroom. The three hundred and fifty assistant. surgeons of the navy, both by their ele. mentary and professional education, as well as from their acquirements in geveral literature, are equal to medical men in civil life, and rank with them as gentlemen. But it is too well known they labour under great disadvantages, and their discomferts are very glaring: instead of receiving the respect due to them from their profession and standing as gentlemen, their nuess-place is that with the midshipmen from the age of fourteen to the mate, all so much younger than themselves; where, from morning till night, nothing but jarring and continued noise is to be heard. They turn in to their hammocks at night; rise in the morning; dress by the side of their chest; they can never enjoy sufficient quietude for study to im prove themselves in their profession, or to keep up that which they had already acquired; which is of much greater importance to the service than it is generally allowed to be, and wonld be of great advantage in cases of accident and sickness. An assistant must now continue to serre for ten 